\title{
Maternal assessment of recommendations on the newborn infant care upon hospital discharge
}

\author{
José David Herrero-Morín, M.D., ${ }^{a}$ Belén Huidobro Fernández, B.S., ${ }^{a}$ \\ María Cristina Amigo Bello, B.S., ${ }^{a}$ Rocío Quiroga González, B.S., ${ }^{b}$ and \\ Nuria Fernández González, M.D.c
}

\begin{abstract}
Introduction. It is common for pediatricians to provide parents with information on how to look after their newborn baby at the time of discharge from the hospital. The objectives of this study are to determine the level of satisfaction regarding such information, to be aware of what additional information parents would have liked to receive, and to establish which factors may impact any additional information request.

Population and Methods. Descriptive study evaluating the opinion of women at 5-15 days post- partum regarding such information.

Results. A hundred and seventy-six surveys were collected. Of these, $68.8 \%$ respondents had attended childbirth classes. Sixty-one point four percent referred to have looked for advice on the newborn infant care, mostly on the Internet and in books. Seventy-four point four percent considered that the information provided sufficed. Most commonly, information was requested on breastfeeding (33.3\%), bottle feeding $(20.0 \%)$, and umbilical cord care $(11.1 \%)$. Mothers who requested more information attended childbirth classes more frequently (significant) and searched for information during pregnancy (not significant). In addition, this group significantly assigned a lower score to the opportunity to ask questions and the level of trust on the pediatrician.

Conclusions. Maternal satisfaction regarding the information provided is adequate; and most mothers do not request additional information. The topic on which they most frequently request additional information is breastfeeding. The decision to request information does not depend on maternal age, maternal education, employment condition, or having other children. Likewise, mothers have questions that are not satisfactorily answered during childbirth classes. Key words: healthy newborn infant, postnatal care, postnatal education, transition, information, questionnaire, satisfaction survey.
\end{abstract}

http://dx.doi.org/10.5546/aap.2015.eng.28

\section{INTRODUCTION}

Having a child is considered one of the most significant changes in life. The transition towards parenthood should be a positive experience since it may have a long-term impact on the parent-child relationship. This is also influenced by parents' capability to take on new roles. ${ }^{1}$ Health education on newborn infant care provided after childbirth may help to acquire skills and feel safe on how to look after the baby and to adapt to change. ${ }^{2-4}$ In our field of pediatric care, it is common for pediatricians to provide parents with information on newborn infant care.

At our health facility, parents are provided such information (breastfeeding, umbilical cord care, newborn hygiene, recommendations on sleeping position of babies, screening for metabolic conditions, immunizations, vehicle safety devices, and follow-up at the health facility) upon discharge from the hospital. Pediatricians orally provide this information to every mother/ father, and they also answer questions that may arise. Pediatricians have received previous training so that the information provided to parents is consistent and covers all the above mentioned topics. In addition, the information is summarized and written down on the newborn infant discharge report.

This study is part of a hypothesis that proposes that parents find information provided by healthcare providers on common newborn infant care insufficient or inadequate.

The objectives of this study were to determine the level of satisfaction parents have with the information provided, to know what other information they would have liked to receive, and to establish which factors may impact any additional information request.

\section{POPULATION AND METHODS}

This was a cross-sectional study that included all pregnant women 
who gave birth to a live newborn infant at Hospital Álvarez-Buylla, Spain (Level I Neonatal Unit ${ }^{5}$ ) between January $1^{\text {st }}$ and December $31^{\text {st }}$, 2012 with a gestational age $\geq 35$ weeks. Exclusion criteria were not finding a contact telephone number in the mother's medical record or if the mother was not fluent in Spanish and / or English. Newborn infants who required to be transferred to another hospital and those whose parents were members of the hospital staff or their relatives were excluded to avoid any selection bias. A survey was developed to include sociodemographic outcome measures, antenatal care (attending childbirth classes and their assessment), outcome measures related to childbirth and type of feeding, information offered by the pediatrician at discharge and its assessment (usefulness, opportunity to ask questions to the pediatrician, level of trust on the pediatrician, use of clear language), other information that families would have liked to receive, and search for information on newborn infant care during pregnancy.

The survey was made by telephone; with two contact attempts at each telephone number available between 5 and 15 days of life once the newborn infant had been discharged (before the first follow-up visit at the health facility). All surveys were conducted by the same investigator.

Questions were closed-ended, except for "other information that the family would have liked to receive" and "topics searched during pregnancy." Table 1 details the studied outcome measures.

Outcome measures were analyzed descriptively (SPSS 19.0). Quantitative outcome measures are described using mean, median, standard deviation (SD) and range, except as otherwise indicated; qualitative outcome measures, using proportions. Mothers were instructed to score the different parameters using a 0 (minimum) to 10 (maximum) scale. Quantitative outcome measures were compared using the Student $t$ or Mann-Whitney U tests; qualitative outcome measures, using the Chisquare test, accompanied by Fisher's exact test if necessary. The significance level was established at $p \leq 0.05$. The study was approved by the hospital's Management/Board and the Advisory Commission.

\section{RESULTS}

In the one-year study, there were 367 live births at our hospital, all these newborn infants met the inclusion criteria. Nine were excluded because one of their parents was a member of the hospital staff, and five, because the newborn infant was transferred to another facility. Of the remaining newborn infants, 176 surveys were completed, all were filled in by mothers. Only two families $(0.56 \%)$ refused to participate in the study.

Maternal mean age was 31.9 (4.9) years old, median age: 32 years old, range: $20-43$ years old. Paternal mean age was 34.1 (5.3) years old, median age: 34 years old, range: $20-50$ years old. Table 2 shows maternal sociodemographic characteristics.

Mean gestational age was 39 (1) weeks, range: $35-42$ weeks. Delivery was eutocic in $72.8 \%$ $(128 / 176)$, vacuum extraction was used in $2.8 \%$ $(5 / 176)$ and C-section was performed in $24.4 \%$ $(43 / 176)$. Hospital length of stay for newborn infants was 2.7 (0.9) days.

At the time of the survey, $79.5 \%(140 / 176)$ were under exclusive breastfeeding, 10.8\% (19/176) under mixed feeding, and 9.7\% (17/176) under bottle-feeding. A higher percentage of breastfeeding was observed among women without previous children: $95.4 \%(103 / 108)$, exclusive breastfeeding: $82.4 \%(89 / 108)$, versus those who had previous children: $82.1 \%$ (55/67), exclusive breastfeeding: $76.1 \%(51 / 67), p<0.01$.

Most women had attended childbirth classes $(68.8 \%, 121 / 176)$. Of the 55 mothers who did not attend childbirth classes, $49.1 \%$ (27/55) explained that it was due to timetable problems, $45.5 \%$ $(25 / 55)$ considered it was unnecessary, and $1.8 \%$ (1 patient) indicated there were no vacancies. Survey respondents who had attended childbirth classes assigned a score of 8.5 (1.4) points to the usefulness of classes in relation to newborn infant care. In terms of parity, a significantly lower frequency of attendance to childbirth classes was observed among women with previous children (33.3\% versus $88.0 \%, 25 / 67$ versus $95 / 108, p$ $<0.01)$. No differences were observed in the assessment of class usefulness among those who did attend childbirth classes from both groups. Among mothers who did not attend childbirth classes, those with previous children indicated that they considered it unnecessary $(54.8 \%, 23 / 42)$ or had timetable problems $(42.9 \%, 18 / 42)$, while most women without previous children referred that this was related to timetable problems $(62.2 \%, 9 / 13, p<0.05)$.

A total of $61.4 \%(108 / 176)$ of mothers indicated that they had looked for information 
on newborn infant care during pregnancy. Most of them used the Internet $(53.7 \%, 58 / 108)$, books $(48.1 \%, 52 / 108)$ and magazines $(42.6 \%, 46 / 108)$ and, to a lesser extent, they obtained information from friends $(5.6 \%, 6 / 108)$, relatives $(4.6 \%, 5 / 108)$ and other means $(2.8 \%, 3 / 108)$. Table 3 shows the topics searched for by mothers during pregnancy. Most women without previous children had looked for information during pregnancy $(77.8 \%, 84 / 108)$, while most women with previous children had not $(35.8 \%, 24 / 67, p<0.01)$.

As far as the information received, Table 4 shows the percentage of mothers who said they had received information on different topics upon hospital discharge and their assessment of such information. Information was considered sufficient by $74.4 \%(131 / 176)$ of mothers, while $25.6 \%(45 / 176)$ indicated that they would have liked to receive additional information. Table 5 shows the topics on which they would have liked to receive additional information. Maternal assessment of the opportunity to ask questions to the pediatrician was scored 9.20 (1.97) points, the level of trust on the pediatrician scored 9.15 (1.30) points, and language clarity, 9.43 (1.11) points. No differences were observed among women with and

TABLE 1. Analyzed outcome measures

\begin{tabular}{|c|c|}
\hline Age & $\begin{array}{l}\text { - Mother } \\
\text { - Father }\end{array}$ \\
\hline Maternal sociodemographic characteristics & $\begin{array}{l}\text { - Nationality } \\
\text { - Marital status } \\
\text { - Education level } \\
\text { - Employment condition } \\
\text { - Previous children }\end{array}$ \\
\hline Attendance to childbirth classes (yes/no) & $\begin{array}{l}\text { - If "yes," women were asked to score its usefulness (0-10 scale) } \\
\text { - If "no," they were asked to give a reason (consider it unnecessary, } \\
\text { nawareness regarding childbirth classes, no vacancies, timetable } \\
\text { roblems, do not know / do not answer) }\end{array}$ \\
\hline Type of delivery & $\begin{array}{l}\text { - Eutocic } \\
\text { - Assisted (vacuum, forceps) } \\
\text { - C-section }\end{array}$ \\
\hline \multicolumn{2}{|l|}{ Gestational age } \\
\hline \multicolumn{2}{|l|}{ Hospital length of stay (days) } \\
\hline $\begin{array}{l}\text { Type of feeding at the } \\
\text { time of the survey }\end{array}$ & $\begin{array}{l}\text { - Breastfeeding } \\
\text { - Bottle feeding } \\
\text { - Mixed feeding }\end{array}$ \\
\hline $\begin{array}{l}\text { Information received at discharge (yes } / \text { no) } \\
\text { Note: If "yes," women were asked to assess } \\
\text { the information ( } 0-10 \text { scale) }\end{array}$ & $\begin{array}{l}\text { - Newborn infant physical examination at discharge } \\
\text { - Breastfeeding, bottle feeding } \\
\text { - Umbilical cord care } \\
\text { - Bathing } \\
\text { - Hygiene/diaper changing } \\
\text { - Sleeping position } \\
\text { - Screening for metabolic conditions } \\
\text { - Immunizations } \\
\text { - Vitamin prophylaxis (vitamin D) } \\
\text { - Vehicle safety devices } \\
\text { - Follow-up at health facility }\end{array}$ \\
\hline
\end{tabular}

Opportunity to ask questions to the pediatrician providing information at discharge (0-10 scale)

Level of trust on the pediatrician providing information at discharge (0-10 scale)

Clarity of language used by pediatrician providing information at discharge (0-10 scale)

Additional information the family would have liked to receive

Information search during pregnancy or after childbirth (yes/no)

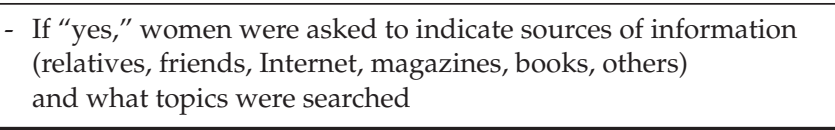


without previous children in relation to information assessment for any topic or the opportunity to ask questions, the level of trust on the pediatrician or language clarity. The percentage of mothers who requested additional information was higher in the group without previous children, but no statistical significance was observed: $30.6 \%(33 / 108)$ versus $17.9 \%$ (12/67) among women with previous children.

Significant differences are observed in Table 6 when comparing the groups of mothers who had and had not requested additional information. Attending childbirth classes was significantly more common among those who had requested additional information, although there was no difference in the assessment on their usefulness between both groups. No significant differences were found in terms of maternal age, education level, employment condition or having previous children. There were significant differences with worse scores assigned by mothers who had requested additional information in relation to the opportunity to ask questions and the level of trust on the pediatrician. The percentage of mothers who searched for information during pregnancy was higher in the group of mothers who had requested additional information, but the difference was not significant.

\section{DISCUSSION}

As part of families adapting to change and taking on the responsibility of looking after their newborn infant, it is recommended that parents receive advice on basic care for the first days of life that will promote the baby's and the family's health and well-being. ${ }^{3,4,6}$ Reducing hospital

TABLE 3. Topics searched by mothers who said they had looked for information during pregnancy $(N=176)$

\begin{tabular}{lcc} 
& n & \% \\
\hline Did not search for information & 68 & 38.6 \\
General information & 49 & 27.8 \\
Breastfeeding & 30 & 17.0 \\
Bathing & 14 & 8.0 \\
Umbilical cord care & 6 & 3.4 \\
Bottle feeding & 5 & 2.8 \\
Abdominal cramps & 5 & 2.8 \\
Massages to the newborn infant & 3 & 1.7 \\
Diaper changing & 2 & 1.1 \\
Clothing/wrapping & 2 & 1.1 \\
Vehicle safety devices & 2 & 1.1 \\
Basic care & 2 & 1.1 \\
Newborn sleep & 2 & 1.1 \\
Others & 6 & 3.4 \\
\hline
\end{tabular}

TABLE 2. Maternal sociodemographic characteristics

\begin{tabular}{|c|c|c|}
\hline & $\mathbf{n}$ & $\%$ \\
\hline $\begin{array}{l}\text { Maternal nationality }(\mathbf{n}=\mathbf{1 7 6}) \\
\text { Spanish } \\
\text { Other }\end{array}$ & $\begin{array}{c}168 \\
8 \\
\end{array}$ & $\begin{array}{c}95.5 \\
4.5 \\
\end{array}$ \\
\hline $\begin{array}{l}\text { Maternal marital status }(\mathbf{n}=\mathbf{1 7 6}) \\
\text { Married } \\
\text { Living with a couple } \\
\text { Single and not living with the newborn's father }\end{array}$ & $\begin{array}{c}117 \\
58 \\
1 \\
\end{array}$ & $\begin{array}{c}66.5 \\
33.0 \\
0.5\end{array}$ \\
\hline $\begin{array}{l}\text { Education level completed by the mother }(n=176) \\
\text { Primary education } \\
\text { Secondary education } \\
\text { University education }\end{array}$ & $\begin{array}{l}39 \\
74 \\
63\end{array}$ & $\begin{array}{l}22.2 \\
42.0 \\
35.8\end{array}$ \\
\hline $\begin{array}{l}\text { Maternal employment condition }(\mathbf{n}=\mathbf{1 7 5}) \\
\text { Active worker } \\
\text { Looking for a job } \\
\text { Unpaid domestic work } \\
\text { Others (student, retired, unpaid leave) } \\
\end{array}$ & $\begin{array}{c}108 \\
34 \\
30 \\
3\end{array}$ & $\begin{array}{c}61.6 \\
19.5 \\
17.1 \\
1.8 \\
\end{array}$ \\
\hline $\begin{array}{l}\text { Previous children }(\mathbf{n}=\mathbf{1 7 5}) \\
0 \\
1 \\
2 \\
3 \\
\text { More than } 3\end{array}$ & $\begin{array}{c}108 \\
64 \\
2 \\
1 \\
0\end{array}$ & $\begin{array}{c}61.6 \\
36.6 \\
1.2 \\
0.6 \\
0.0\end{array}$ \\
\hline
\end{tabular}


length of stay after birth entails making plans at discharge. ${ }^{7}$ However, some authors have pointed out that current postnatal education is not adequately adapted to what parents need in the early postnatal period. ${ }^{1}$ It has even been found that not all women receive information. ${ }^{3}$ Besides, the information provided is rarely standardized and medical literature on this subjects is scarce. ${ }^{7-9}$

This study was intended to determine whether the information provided is useful to parents once they are at home, and what additional information they request regarding neonatal care.

Bibliography was searched and just a few studies similar to ours were found. The lack of publications related to the information provided upon hospital discharge of healthy newborn infants is alarming; we believe it is about time to lay the foundation for providing adequate health education. According to our experience, spending a few minutes providing information on basic newborn infant care may prevent mistakes that are based on cultural beliefs and the subsequent medical consultations.

In our study, most mothers contacted by telephone agreed to participate, similar to what has been observed in other studies conducted among this population group, ${ }^{3}$ which reflects the interest that families have on this subject.

In our sample, two-thirds of survey respondents had attended childbirth classes $(88 \%$ of women without previous children); finding which is consistent with other studies. ${ }^{1,3}$ More than half of the mothers referred to have looked for newborn infant care advice during pregnancy, mostly on the Internet and in books. The type of information searched was mainly general, followed by breastfeeding. In this regard, it should be noted that online information does not always come from reliable and proven sources.

Three-quarters of survey respondents considered that the information received at discharge was sufficient. A prior Spanish study conducted a survey on 50 women with normal newborn infants on the day of discharge from the hospital; $82 \%$ answered that they considered it

TABLE 5. Topics searched by mothers who requested additional information $(\mathrm{N}=45)$

\begin{tabular}{lcc}
\hline & n & \% \\
\hline Breastfeeding & 15 & 33.3 \\
Bottle feeding & 9 & 20.0 \\
Umbilical cord care & 5 & 11.1 \\
Sleeping position & 4 & 8.9 \\
Vitamin prophylaxis & 4 & 8.9 \\
Immunizations & 3 & 6.7 \\
Newborn infant physical examination & 3 & 6.7 \\
General information & 3 & 6.7 \\
Abdominal cramps & 2 & 4.4 \\
Diaper changing/hygiene & 2 & 4.4 \\
Physiological menstrual cycle & 2 & 4.4 \\
Others & 10 & 22.2 \\
\hline
\end{tabular}

TABLE 4. Mothers who referred to have received information upon hospital discharge and assessment of the information received $(N=176)$

\begin{tabular}{|c|c|c|c|}
\hline & \multicolumn{2}{|c|}{$\begin{array}{l}\text { Mothers who } \\
\text { received information }\end{array}$} & \multirow{2}{*}{$\begin{array}{l}\text { Maternal assessment of the } \\
\text { information received (0-10) } \\
\text { Mean (SD) }\end{array}$} \\
\hline & $\mathbf{n}$ & $\%$ & \\
\hline Newborn infant physical examination at discharge & 167 & 94.9 & $8.89(1.28)$ \\
\hline Breastfeeding & 150 & 85.2 & $8.45(1.69)$ \\
\hline Bottle feeding & 110 & 62.5 & $8.36(1.82)$ \\
\hline Umbilical cord care & 132 & 75.0 & $8.96(1.42)$ \\
\hline Bathing & 98 & 55.7 & $8.57(1.76)$ \\
\hline Hygiene/diaper changing & 74 & 42.0 & $8.80(1.70)$ \\
\hline Sleeping position & 141 & 80.1 & $9.06(1.31)$ \\
\hline Screening for metabolic conditions & 172 & 97.7 & $9.35(1.19)$ \\
\hline Immunizations & 124 & 70.5 & $9.29(1.30)$ \\
\hline Vitamin prophylaxis(vitamin D) & 55 & 31.3 & $9.16(1.20)$ \\
\hline Vehicle safety devices & 97 & 55.1 & $9.22(1.23)$ \\
\hline Follow-up at health facility & 160 & 90.9 & $9.30(1.08)$ \\
\hline
\end{tabular}


necessary to receive information before discharge on the care required by both postpartum women and newborn infants, and $20 \%$ indicated that they needed additional information, mostly on general topics and umbilical cord care. ${ }^{3}$ In our case, mothers who requested additional information most frequently indicated that they would have liked to receive more information on breastfeeding and, to a lesser extent, about bottle feeding.

As expected, mothers without previous children requested additional information during pregnancy, similarly to what has been observed in other investigations. ${ }^{3}$ Attending childbirth classes was significantly most common among these women. Actually, first-time mothers who did not attend childbirth classes referred that it was because of timetable problems, while more than half of women with previous children who did not attend these classes indicated that they considered it unnecessary. Although information request following childbirth did not differ significantly between both groups, it was also more frequent among inexperienced mothers than among those with previous children.

It should be noted that, similarly to what has been observed by other authors, ${ }^{3}$ the comparison between women who requested additional information and those who did not showed no significant differences in terms of education level. A previous Australian study conducted a mail survey on mothers six months after childbirth to assess their opinion on newborn infant care

TABLE 6. Comparison between mothers who requested additional information and those who did not

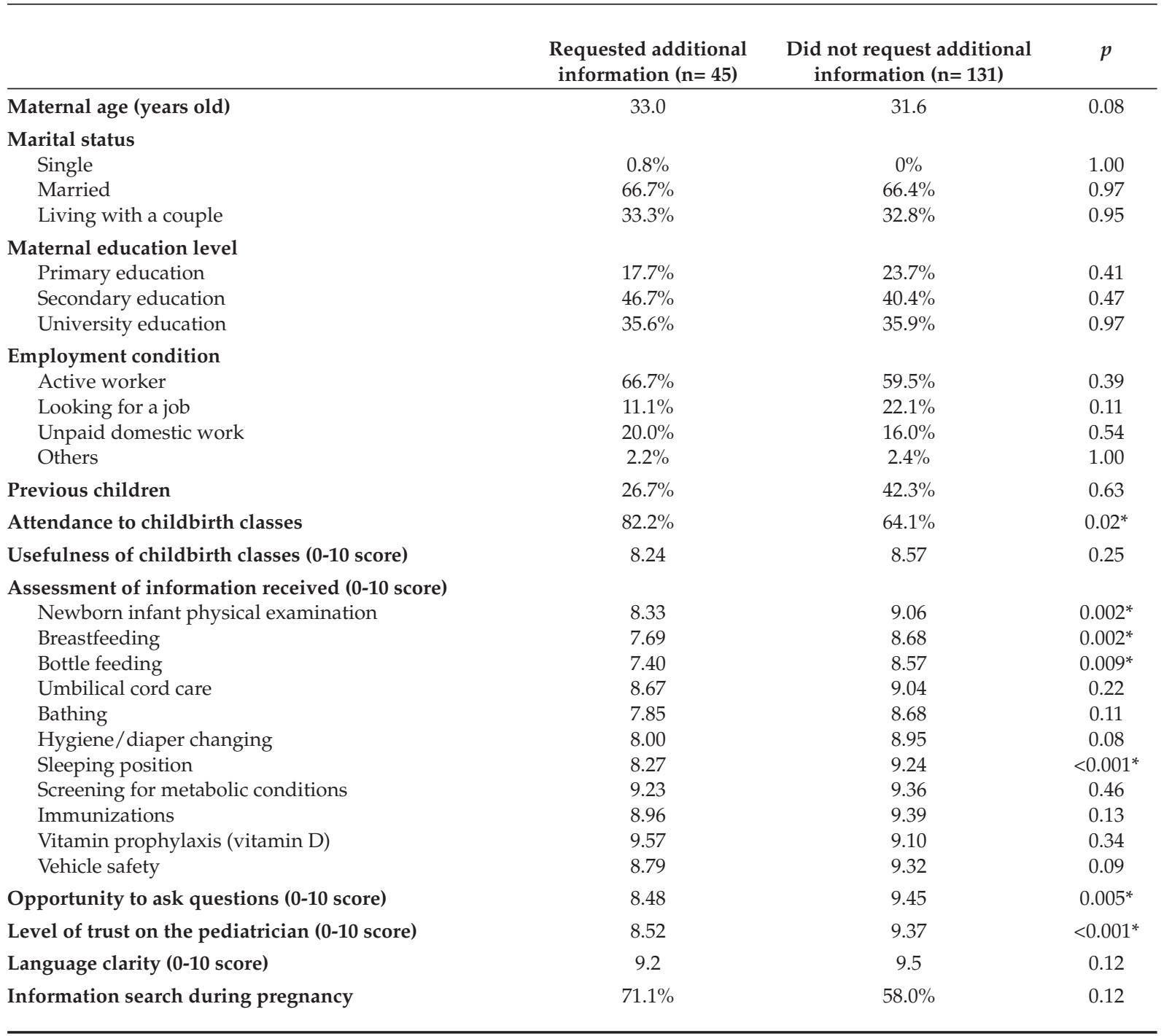

* Statistically significant differences. 
and compared the group who had a very good opinion to the rest, but there were no differences related to age, education level or parity, although lower scores were given by those who were single, had a lower income and were younger than 35 years old. ${ }^{7}$ It could be assumed that a higher maternal education level may help to understand the information received from healthcare professionals or through other means but, as described in our results, newborn infant care is not related to training or a sense of capability to deal with newborn infant care.

Curiously, mothers who requested additional information after giving birth also showed a significantly higher frequency of attendance to childbirth classes and, a higher, though not significant, frequency of information search during pregnancy. This evidences that, for mothers who had doubts or were more interested in receiving information, childbirth classes, which cover newborn infant care, are not enough to completely answer all questions they may have.

It has been recommended that postpartum care should include an appraisal of the level of knowledge and needs so as to establish a standardized education for mothers on how to look after their babies at home. ${ }^{3}$ A Swedish study analyzed how pregnant women/mothers perceive care received at 16 weeks of gestation, and at 2 months and 1 year after giving birth. It established a relationship among the source of dissatisfaction inside the hospital and inflexible timetables for information provision, lack of privacy, and the level of satisfaction with the time spent (which they rarely considered excessive). ${ }^{8}$ Although the bibliography suggests that mothers are prepared to receive information 24 hours after giving birth, ${ }^{1}$ it appears that, at that time, feeling tired or other distractions may have a negative impact on their capacity to focus. ${ }^{10}$ Some authors have successfully proven that a simple intervention, such as helping women to take notes, may improve recommendation follow-up, especially for firsttimers. $^{10}$

Our study has certain limitations. The first limitation is that not all mothers were surveyed because it was not possible to contact them by telephone. The second limitation is that answers that offer an assessment of different parameters are subjective and do not accurately reflect the quality or range of information provided since mothers do not have access to standardized information to which to compare it. Given the small sample size and the geographic restriction to a single hospital it is not possible to generalize results. However, conclusions drawn may facilitate future research on the studied field and enable the comparison of results obtained at other facilities with similar or different practices for providing postpartum information.

\section{CONCLUSION}

In general, mothers are satisfied with the information they are provided since most of them did not request additional information. The topic on which they most frequently would have liked to receive information is breastfeeding. No significant differences were observed in terms of maternal age, education level or having previous children among the mothers who requested additional information and those who did not. Finally, attending childbirth classes is not sufficient to completely clear doubts that mothers may have.

\section{Acknowledgments}

We would like to thank the mothers for helping us with during study.

\section{REFERENCES}

1. McKellar LV, Pincombe JI, Henderson AM. Insights from Australian parents into educational experiences in the early postnatal period. Midwifery 2006;22(4):356-64.

2. Persson EK, Fridlund B, Kvist LJ, Dykes AK. Mothers' sense of security in the first postnatal week: interview study. $J$ Adv Nur 2011;67(1):105-16.

3. Ponce Capitán MA. Conocimientos de las puérperas sobre autocuidados y cuidados del recién nacido en el momento del alta hospitalaria. Matronas Prof 2005;6(3):14-9.

4. Forster DA, McLachlan HL, Rayner J, Yelland J, et al. The early postnatal period: exploring women's views, expectations and experiences of care using focus groups in Victoria, Australia. BMC Pregnancy Childbirth 2008;8:27.

5. Sánchez Luna M, Pallás Alonso CR, Botet Mussons F, Echániz Urcelay I, et al. Recomendaciones para el cuidado y atención del recién nacido sano en el parto y en las primeras horas después del nacimiento. An Pediatr (Barc) 2009;71(4):349-61.

6. Rite García S, Fernández Lorenzo JR, Echániz Urcelay I, Botet Mussons F, et al. Niveles asistenciales y recomendaciones de mínimos para la atención neonatal. An Pediatr (Barc) 2013;79(1):51.e1-51.e11.

7. Brown SJ, Davey MA, Bruinsma FJ. Women's views and experiences of postnatal hospital care in the Victorian Survey of Recent Mothers 2000. Midwifery 2005;21(2):109-26.

8. RudmanA, El-Khouri B, Waldenström U. Evaluating multidimensional aspects of postnatal hospital care. Midwifery 2008;24(4):425-41.

9. Díaz-Sáez J, Catalán-Matamoros D, Fernández-Martínez MM,Granados-GámezG. La comunicación yla satisfacción de las primíparas en un servicio público de salud. Gac Sanit 2011;25(6):483-9.

10. Kistin CJ, Barrero-Castillero A, Lewis S, Hoch R, et al. Maternal note-taking and infant care: a pilot randomized controlled trial. Arch Dis Child 2012;97(10):916-8. 